\title{
Staphylococcal superantigens in colonization and disease
}

\author{
Stacey X. X $\mathbf{u}^{1}$ and John K. McCormick ${ }^{1,2 *}$ \\ Department of Microbiology and Immunology, Centre for Human Immunology, Schulich School of Medicine and Dentistry, University of Western Ontario, \\ London, ON, Canada \\ 2 Lawson Health Research Institute, London, ON, Canada
}

\author{
Edited by: \\ Martin J. McGavin, University of \\ Western Ontario, Canada \\ Reviewed by: \\ Thomas Proft, University of \\ Auckland, New Zealand \\ Victor J. Torres, New York University \\ School of Medicine, USA

\section{*Correspondence:} \\ John K. McCormick, Department of \\ Microbiology and Immunology, \\ University of Western Ontario, 1151 \\ Richmond St., London, ON N6A \\ 5C1, Canada. \\ e-mail: john.mccormick@ \\ schulich.uwo.ca
}

Superantigens (SAgs) are a family of potent immunostimulatory exotoxins known to be produced by only a few bacterial pathogens, including Staphylococcus aureus. More than 20 distinct SAgs have been characterized from different S. aureus strains and at least $80 \%$ of clinical strains harbor at least one SAg gene, although most strains encode many. SAgs have been classically associated with food poisoning and toxic shock syndrome (TSS), for which these toxins are the causative agent. TSS is a potentially fatal disease whereby SAg-mediated activation of T cells results in overproduction of cytokines and results in systemic inflammation and shock. Numerous studies have also shown a possible role for SAgs in other diseases such as Kawasaki disease (KD), atopic dermatitis (AD), and chronic rhinosinusitis (CRS). There is also now a rich understanding of the mechanisms of action of SAgs, as well as their structures and function. However, we have yet to discover what purpose SAgs play in the life cycle of $S$. aureus, and why such a wide array of these toxins exists. This review will focus on recent developments within the SAg field in terms of the molecular biology of these toxins and their role in both colonization and disease.

Keywords: superantigen, staphylococcal enterotoxin, Staphylococcus aureus, colonization

\section{INTRODUCTION}

Bacterial superantigens (SAgs) represent a unique class of exotoxins which all function to activate enormous numbers of $\mathrm{T}$ lymphocytes (McCormick et al., 2001; Llewelyn and Cohen, 2002; Proft and Fraser, 2003). Although only a few SAgs have clear associations with specific human diseases, bacterial genome sequencing projects over the last decade have led to the characterization of a large and expanding family of exotoxins that includes many genetically and antigenically distinct proteins. These are found primarily in Staphylococcus aureus and Streptococcus pyogenes, but also found in a few other species of $\beta$-hemolytic streptococci, coagulase negative staphylococci, Mycoplasma arthritidis, and Yersinia pseudotuberculosis. In the following sections, we will update recent findings in the biochemistry of staphylococcal SAgs, and explore the role of SAgs in different lifestyles of $S$. aureus in the context of both infection and nasal colonization.

\section{THE SUPERANTIGEN SUPERFAMILY}

The staphylococcal SAgs include the staphylococcal enterotoxins (SEs), the staphylococcal enterotoxin-like (SEls) proteins, and toxic shock syndrome toxin-1 (TSST-1) (Lina et al., 2004). The SEs were originally defined by their ability to cause staphylococcal food poisoning (SFP) including emesis, and currently include the SEs A, B, C, D, E, G, H, I, R, and T. The SEl toxins, although both homologous and structurally similar to the SEs, either do not induce emesis, or have not been formally demonstrated to induce emesis, and include the SEls J, K, L, M, N, O, P, Q, S, U, V, and $\mathrm{X}$. It is important to note that although designated as a "SEl" toxin, some of these may possess undemonstrated emetic activity and be reclassified in the future as bona fide enterotoxins.
An updated phylogenetic classification scheme of the SAg exotoxins (McCormick et al., 2001) is shown in Figure 1 where SAgs from staphylococci and streptococci are placed into five evolutionary groups. TSST- 1 sits as an evolutionarily distinct SAg that does not induce emesis (Schlievert et al., 2000) and is the only member of the Group I SAgs. TSST- 1 is believed to be the major, if not sole cause of the menstrual form of toxic shock syndrome (TSS) (Bergdoll et al., 1981; Schlievert et al., 1981). The Group II SAgs contain both staphylococcal and streptococcal SAgs including SEB, SEC, and streptococcal pyrogenic exotoxin A (SpeA). After TSST-1, SEB has been historically most commonly linked with non-menstrual-associated cases of staphylococcal TSS (Schlievert, 1986), while SpeA has been historically most commonly linked with streptococcal TSS (Stevens et al., 1989). The Group III SAgs include only staphylococcal SAgs, and in general terms, this Group contains SAgs most commonly associated with SFP such as SEA, SED, and SEE, although the Group II SAgs SEB and SEC are often implicated as well (Argudin et al., 2010). Both Group II and III SAgs contain a unique "cysteine-loop structure" that is important for emetic activity (Hovde et al., 1994). The Group IV SAgs are only populated by streptococcal SAgs and will not be discussed here. The Group V SAgs, contain mostly staphylococcal SAgs (except SpeI and related orthologues), and other than SEI which has weak emetic activity, consists of only $\mathrm{SEl}$ toxins. In fact, SEI is the only SAg outside of the Group II and III SAgs demonstrated to have emetic activity, although this only occurred in one of four animals tested (Munson et al., 1998). Very recently, SEl-X was described as a novel SAg that does not align well within the currently classification system, but is encoded within the core chromosome of most $S$. aureus strains (Wilson et al., 2011). Also of note are the staphylococcal superantigen-like 
proteins (SSLs) (Langley et al., 2010), and although these are also structurally similar to the staphylococcal superantigens (Baker et al., 2007; Chung et al., 2007; Ramsland et al., 2007) they do not possess SAg activity and will not be discussed within this review.

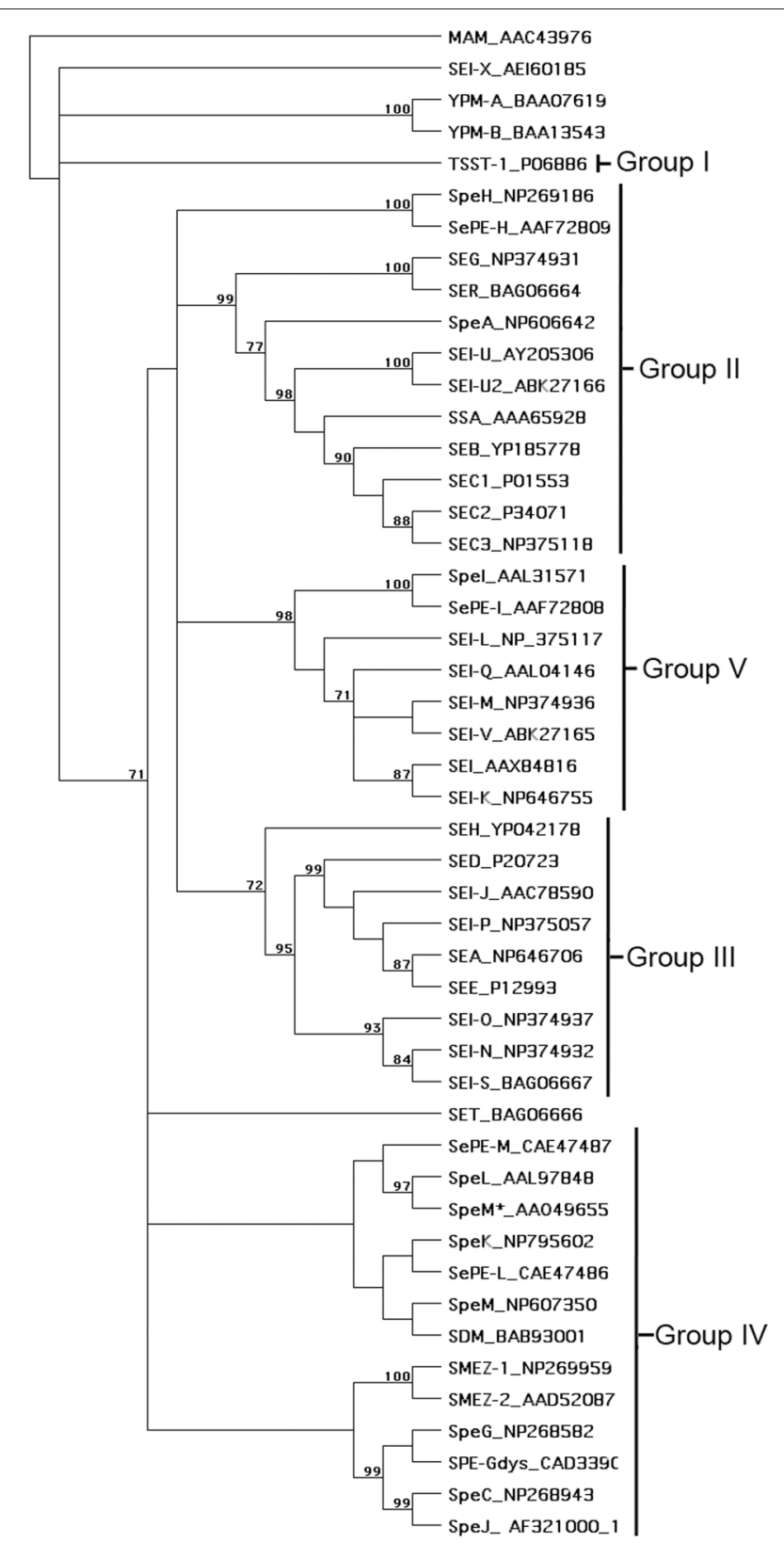

FIGURE 1 | Phylogenetic tree of known bacterial SAgs. The unrooted tree was based on the alignment of amino acid sequences constructed with the unweighted pair group method using arithmetic averages (UPGMA) in MacVector 7.2.3. The SAg abbreviations are indicated followed by the relevant accession number. As previously proposed (McCormick et al., 2001), the five main groups of SAgs belonging to the pyrogenic toxin class are indicated. MAM, YPM, and non-Group A streptococcal SAgs are also included in the analysis. The number of times each branch was supported from 1000 bootstraps is shown as a percentage.

\section{CONVENTIONAL VERSUS SUPERANTIGEN-MEDIATED T CELL ACTIVATION}

Normal T cell-mediated immunity is initiated through the interaction of an $\alpha \beta$ T cell receptor (TCR) and a processed peptide antigen presented within self-major histocompatibility (pMHC) complexes (Figure 2A) (Garcia et al., 1999; Garcia and Adams, 2005). If the TCR specifically recognizes the antigen as foreign, these interactions will activate the tyrosine kinase Lck (associated with co-receptors CD4 and CD8), which in turn will activate downstream cell signaling resulting in activation of transcription factors to induce $\mathrm{T}$ cell proliferation and differentiation (Smith-Garvin et al., 2009). As TCRs are extraordinarily diverse molecules, only $\sim 0.01 \%$ of naïve $\mathrm{T}$ cells will recognize a given antigen (Givan et al., 1999).

SAg-mediated $\mathrm{T}$ cell activation is both quantitatively and qualitatively distinct from conventional $\mathrm{T}$ cell activation (Bueno et al., 2007). As the defining feature of the SAg toxin is the ability to activate $\mathrm{T}$ lymphocytes in a TCR $\beta$-chain variable domain (Vß)-dependent manner (Marrack and Kappler, 1990), very large
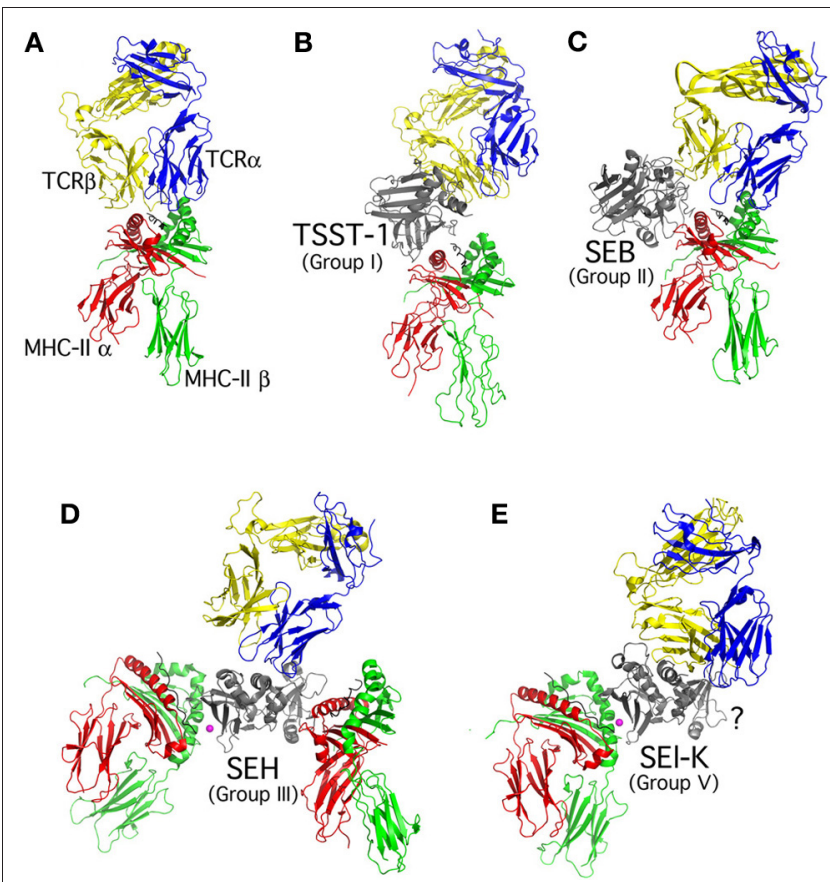

FIGURE 2 | Structural overview of the SAg-mediated T cell activation complexes. Ribbon diagram models show (A) conventional T cell activation (Hennecke et al., 2000), and SAg-mediated T cell activation complexes for (B) Group I (e.g., TSST-1) (C) Group II (e.g., SEB) (D) Group III (e.g., SEH) and (E) Group V (e.g., SE/-K). Colors for TCR and MHC class II chains are labeled in Panel (A). The SAg activation complex models were generated by superposition of the TSST-V $\beta$ (Moza et al., 2007) and TSST-MHC class II (Kim et al., 1994) structures, the SEC-V $\beta$ (Fields et al., 1996) and SEB-MHC class II (Jardetzky et al., 1994) structures, the SEH-V $\alpha$ V $\beta$ (Saline et al., 2010), SEH-MHC class II $\beta$-chain (Petersson et al., 2001), and the SEA-MHC class II $\alpha$-chain (Petersson et al., 2002) structures, and the SEK-V $\beta$ (Gunther et al., 2007) and SEI-MHC II (Fernandez et al., 2006) structures. The TCR $\alpha$-chain was modeled for clarity in each case from the conventional complex (Hennecke et al., 2000). The "?" in Panel (E) indicates that there is no current information regarding the presence, or absence, of the generic low-affinity MHC class II binding domain for Group V SAgs. 
numbers of T cells can be activated upon SAg exposure. Although TCRs are extraordinarily diverse molecules, this diversity is concentrated within the CDR3 loops due to $\mathrm{V}(\mathrm{D}) \mathrm{J}$ (somatic) recombination during $\mathrm{T}$ cell development. However, there are a relatively limited number of possible TCR V $\beta$ regions $(\sim 50$ are functionally expressed in humans), and thus SAgs can activate $\mathrm{T}$ cells in orders of magnitude above conventional processes. SAgs also do this in an extremely potent manner, and in general, most SAgs can induce measurable activation of T cells in the picogram $\left(10^{-12} \mathrm{~g}\right)$ concentration range. It is often assumed that SAgmediated $\mathrm{T}$ cell activation follows the normal signaling rules for conventional pMHC-mediated $\mathrm{T}$ cell activation and indeed this is the case with at least one major distinction. As predicted, TCR ligation by SAg will induce signals through Lck (Morgan et al., 2001), although Lck signaling is not actually required (Yamasaki et al., 1997; Bueno et al., 2006). However, signaling can proceed in the absence of Lck through a G $\alpha 11 /$ PLC $\beta$-dependent pathway that converges with the canonical Lck-dependent pathway at the level of ERK1/2 (Bueno et al., 2006). Since one function of the CD4/CD8 co-receptors is the recruitment of Lck, the ability of SAgs to bypass Lck is also likely related to the capability of SAgs to activate both $\mathrm{CD}^{+}{ }^{+}$and $\mathrm{CD}^{+}{ }^{+} \mathrm{T}$ cells, despite cross-linking with MHC class II molecules (Herrmann et al., 1992; Fuller and Braciale, 1998).

The human immune system has evolved to be able to recognize and eliminate pathogens and their antigens. However, SAgs represent the only known microbial virulence factor whose primary role is to deliberately force the activation of the adaptive immune system. This is counter-intuitive given the numerous staphylococcal virulence factors apparently designed for immune subversion and evasion (Nizet, 2007). This leads to the question as to why S. aureus produce SAgs. Given the wide variety and high prevalence of SAg genes, it is likely that these genes would be lost, especially since they are primarily encoded on mobile genetic elements, without a contribution to the fitness of $S$. aureus. The influence and architecture of SAg-encoding mobile genetic elements has been the subject of a comprehensive review in this issue (McGavin et al., 2012).

$\mathrm{T}$ cell anergy, a phenomenon where $\mathrm{T}$ cells become unresponsive to stimulation, has long been proposed to be an immune subversion tactic of $S$. aureus. Several studies have shown this ex vivo following in vivo stimulation (Kawabe and Ochi, 1990; Rellahan et al., 1990; Lee and Vitetta, 1992; Miller et al., 1999). However, SAg-induced anergy produced ex vivo does not necessarily translate into in vivo anergy (Heeg et al., 1995). In addition, high levels of purified toxin are often used in experimental mouse models that may not reflect physiological conditions. Also, there is no evidence to suggest that $\mathrm{T}$ cells are exhausted in nasal carriers of toxigenic $S$. aureus strains. Recently, a case study of TSS (likely induced by TSST-1) showed deletion followed by an expansion in the $\mathrm{V} \beta 2^{+}$subset that normalized 70 days post-convalescence. In this important study, re-stimulation of peripheral blood mononuclear cells (PBMCs) taken during the acute phase of disease with exogenous SAg resulted in proliferation of $\mathrm{VB2}^{+}$cells suggesting that $\mathrm{T}$ cells were not rendered anergic (Rasigade et al., 2011). Recurrent cases of TSS occur, usually as a combined result of insufficient eradication of $S$. aureus and the inability to form anti-SAg antibodies. The proliferative response of T cells was assessed from a patient with recurrent TSS and there was no reduction in the ability of the patients $T$ cells to respond in vitro (Arvand and Hahn, 1996). Thus, at least in some patients, true anergy of $\mathrm{V} \beta$ specific $\mathrm{T}$ cell subsets may not occur and suggests that this activity is not the purpose of SAg activity for $S$. aureus. Recurrent TSS also implies that T cells are not rendered anergic as they are able to react to SAg stimulation during multiple episodes.

Recently, Taylor and Llewelyn (2010) demonstrated that human PBMCs exposed to SAgs resulted in a dose-dependent, V $\beta$ specific increase in CD25+ FoxP3 + cells, indicative of a regulatory $\mathrm{T}$ cell (Treg) phenotype. The immunosuppressive qualities of these SAg-induced Tregs have been attributed to the expression of IL-10 and may have a role in prolonging commensalism (Taylor and Llewelyn, 2010).

\section{STAPHYLOCOCCAL SUPERANTIGENS AND THEIR HOST RECEPTORS}

SAg pro-toxins include a secretion signal that is cleaved from the $\mathrm{N}$-terminus upon export via the general Sec-dependent secretion pathway. SAgs are released as non-enzymatic, relatively small proteins, with the final toxin product ranging in size from $\sim 22$ to $29 \mathrm{kDa}$. All SAgs are made of two structurally similar domains, linked through a central $\alpha$-helix. The larger N-terminal domain contains a $\beta$-barrel motif similar to an OB-fold, while the smaller $\mathrm{C}$-terminal domain contains the $\beta$-grasp motif, which is similar to immunoglobulin-binding domains (Mitchell et al., 2000).

Pioneering crystallographic studies with staphylococcal enterotoxins B in complex with human leukocyte antigen (HLA)-DR1 (Jardetzky et al., 1994), and SEC3 in complex with the mouse TCR Vß8.2-chain (Fields et al., 1996), established a molecular framework by how SAgs can activate so many $\mathrm{T}$ cells (Li et al., 1999). These studies demonstrated that SAgs bind to lateral surfaces of both TCRs, and pMHC class II molecules, to "distort" the normal TCR-pMHC II interaction, such that the CDR3 loops of both TCR $\alpha$ - and $\beta$-chains (which are key for antigen recognition) are wedged away from the antigenic peptide (Figures 2B-E). Through this mechanism, activation of the $\mathrm{T}$ cell is no longer antigen specific, but now dependent upon which V $\beta$ s can be bound by that particular SAg explaining how SAgs are V $\beta$-specific (Li et al., 1999). Large numbers of SAg-activated T cells can then release a multitude of proinflammatory cytokines which in severe cases may lead to the "cytokine storm" phenomenon characteristic of TSS (McCormick et al., 2001). Activation of antigen presenting cells (APCs) by SAgs also contributes to cytokine release due to the involvement of MyD88, which upregulates NF- $\kappa \mathrm{B}$, leading to production of proinflammatory molecules (Kissner et al., 2011).

Recent years have seen a number of further advances in the structural characterization of the staphylococcal SAgs, and there is now a broader picture as to how SAgs from the different evolutionary groups (Figure 1) function to distort the normal process of $\mathrm{T}$ cell activation (Figure 2). For example, the Group I SAg TSST-1 (Figure 2B), which is extremely specific for the human $\mathrm{V} \beta 2^{+} \mathrm{T}$ cells (Choi et al., 1989), forms a unique T cell activation 
complex by binding the MHC II $\alpha$-chain through a relatively low-affinity interface that is highly influenced by different antigenic peptides within MHC II (Kim et al., 1994; Wen et al., 1996). Also, TSST-1 recognizes unique amino acid insertions from V $\beta 2$ within both CDR2 and framework region (FR) 3, explaining the extreme V $\beta$-specificity of this SAg (Moza et al., 2006, 2007; Rahman et al., 2011). There are no direct TCR-MHC II contacts in this T cell activation complex. Group II SAgs (Figure 2C) such as SEB, SEC3, and SpeA, are more "promiscuous" in their V $\beta$ targets, and engage TCR V $\beta$ through "conformation-dependent" mechanisms that are thought to be less dependent on specific V $\beta$ amino acid side-chains (Fields et al., 1996; Li et al., 1998; Sundberg et al., 2002). These SAgs bind the MHC II $\alpha$-chain through an N-terminal, low-affinity binding domain, yet in contrast to TSST-1, this binding is antigenic peptide-independent (Jardetzky et al., 1994). Group III SAgs (Figure 2D) consist of only staphylococcal SAgs, and these toxins are thought to be able to cross-link MHC II molecules (Abrahmsen et al., 1995; Hudson et al., 1995) through both a low-affinity site similar to Group II, (Petersson et al., 2002) as well as a high-affinity, zinc-dependent MHC II $\beta$-chain interface located within the $\beta$-grasp domain of the SAg (Petersson et al., 2001). The only structural information for how Group III SAgs engage TCR is for SEH (Saline et al., 2010), which represents somewhat of an outlier within Group III, and is the only known V $\alpha$-specific SAg (Petersson et al., 2003; Pumphrey et al., 2007). Group IV SAgs are restricted to only streptococcal members, and these toxins bind $\mathrm{V} \beta$ similar to the Group II SAgs, although with a larger footprint (Sundberg et al., 2002), and contain a high-affinity MHC II $\beta$-chain binding domain similar to Group III (Li et al., 2001). Considerable evidence indicates the presence of a low-affinity MHC II $\alpha$-chain interaction, likely similar to Group II (Swietnicki et al., 2003; Tripp et al., 2003; Kasper et al., 2008), although this interaction has not been characterized structurally. The Group V SAgs contain a high-affinity MHC II $\beta$-chain binding domain (Fernandez et al., 2006) similar to Group III, and bind the TCR V $\beta$ with a more "lateral" position extending into FR4 (Figure 2E) (Gunther et al., 2007). There is currently no information relating to the presence, or absence, of the generic low-affinity MHC II interface with Group V SAgs.

Within the SAg family of toxins, each member is able to efficiently activate large numbers of $\mathrm{T}$ cells, regardless of subtle, or dramatic, differences within the different SAg-mediated $\mathrm{T}$ cell activation complexes. However, the one common structural feature of all characterized SAgs, with the exception of the $\mathrm{V} \alpha$-specific SEH, is the engagement of the V $\beta$ CDR2 loop, and this loop appears to be the critical determinant for $\mathrm{V} \beta$-specificity (Rahman et al., 2011).

Recently, it was demonstrated that SEB can bind to the costimulatory molecule CD28, which is constitutively expressed on naïve T cells and binds B7 ligands on APCs. The CD28 binding site is divergent from both the TCR and MHC II binding domains of SEB, and is relatively conserved amongst the SAg family. Disruption of CD28 binding by peptide antagonists reduced mortality rates in mice administered with $\mathrm{D}$-galactosamine and SEB by downregulating Th1, but not Th2 cytokines (Arad et al., 2011). These lines of evidence support the proposal that CD28 binding by SAgs is important to the function of SAgs. Further research elucidating downstream mechanisms will clarify the exact role of CD28 during $\mathrm{T}$ cell activation by SAgs.

\section{STAPHYLOCOCCAL SUPERANTIGENS AND DISEASE STAPHYLOCOCCAL FOOD POISONING}

The first disease linked to the staphylococcal SAgs was SFP, and evidence that a staphylococcal toxin caused the illness dates back to 1930 , where filterable supernatants from a "yellow staphylococcus" was able to induce SFP in human volunteers (Dack et al., 1930; Jordan, 1930). The role of the staphylococcal SAgs in foodborne disease has been reviewed recently in detail (Argudin et al., 2010; Hennekinne et al., 2011), and will not be discussed here.

\section{TOXIC SHOCK SYNDROME}

The other human disease clearly caused by the staphylococcal SAgs is TSS. This disease was described in 1927 by Franklin Stevens as staphylococcal scarlet fever (Stevens, 1927), and was named "toxic shock syndrome" by Todd and colleagues in 1978 to describe a systemic illness in seven children caused by noninvasive S. aureus (Todd et al., 1978). The pathogenesis of TSS is due to a SAg-induced cytokine storm owing to the massive activation of $\mathrm{T}$ cells in individuals lacking neutralizing antibodies to the particular SAg [reviewed in (McCormick et al., 2001)]. The disease is a capillary leak syndrome where patients develop fever, rash, hypotension, multiorgan involvement and convalescent desquamation (McCormick et al., 2001). S. aureus can cause the menstrual form of TSS, which historically occurred in young women in association with high absorbency tampons, and nonmenstrual TSS, which can occur from virtually any S. aureus infection, although infrequently from bacteremia (McCormick et al., 2001). Although most staphylococcal SAgs are functionally capable of inducing TSS in experimental animals, only a few select SAgs have historically been associated with the disease. This is somewhat surprising given the large "collection" of these extremely potent toxins. The TSST-1 SAg was linked to the menstrual form of TSS in 1981 (Bergdoll et al., 1981; Schlievert et al., 1981), although it is also clear that other SAgs, primarily TSST-1, SEB and SEC, are capable of causing the non-menstrual form (Bohach et al., 1990; McCormick et al., 2001).

During the early 1980s, there were a high number of menstrual TSS cases in young women associated with the use of high absorbency tampons (Shands et al., 1980) and the estimated incidence of all forms of TSS at this time was 13.7/100,000 (Osterholm and Forfang, 1982). By the mid-1980s, following the removal of these products from the marker, and public awareness campaigns as well as product labeling, the overall incidence dropped to $0.53 / 100,000$ with a case-fatality rate of $\sim 4 \%$ (Gaventa et al., 1989). A recent population based surveillance for TSS in Minnesota between 2000 and 2006 demonstrates that this rate has been relatively stable and that TSST-1 was still the major cause in most cases (DeVries et al., 2011). Of note, although the community acquired MRSA clonal strain USA300 has dramatically increased in prevalence in the U.S., this strain does not appear to cause many cases of TSS (DeVries et al., 2011). Although the overall incidence of TSS appears low, it has 
been suggested that severe SAg-mediated disease remains underreported (DeVries et al., 2011), due to both the strict CDC case definition (Centers for Disease Control and Prevention, 2011) as well as prompt and appropriate medical attention that would prevent the most severe forms of SAg intoxication. Indeed, TSS is still a major problem, and cases of non-menstrual TSS pediatric burn patients can be extremely dangerous if not recognized early (White et al., 2005).

Apart from the more overt forms of SAg-mediated diseases, there is significant evidence that SAgs also can play a role in a number of other diseases and these will be discussed below.

\section{KAWASAKI DISEASE}

Kawasaki Disease (KD) was first described by Tomisaku Kawasaki in 1967 (Van Crombruggen et al., 2011) and is now the leading cause of acquired heart disease in children from developed nations. KD is an acute, self-limiting vasculitis, typically affecting the coronary arteries, and thought to be triggered by an infectious agent in genetically susceptible individuals (Yeung, 2010). Although the etiology of KD is not known, there is compelling evidence that bacterial SAgs are involved, and could be causal in association with host genetic factors (Matsubara and Fukaya, 2007). First, the clinical presentation of KD has features reminiscent of TSS, including fever, a desquamating rash and erythema of the mucous membranes. SAg producing $S$. aureus and S. pyogenes have been isolated from KD patients, and seroconversion with anti-SAg antibodies has also been demonstrated. Perhaps the strongest evidence of SAg involvement however, is the demonstration of V $\beta$ skewing in KD patients (Abe et al., 1992). A number of studies have found primarily V $\beta 2$ expansion (Leung et al., 1995b) providing a link to either TSST-1 or SpeC which are both V $\beta 2$ specific (Rahman et al., 2011). Others, however, have found expansion of various $\mathrm{V} \beta$ families (Nomura et al., 1998; Yoshioka et al., 1999), potentially implicating other SAgs with different $\mathrm{V} \beta$ profiles. Treatment of $\mathrm{KD}$ involves the use of intravenous immunoglobulin (IVIG) (Newburger et al., 1986), and IVIG is well known to contain SAg neutralizing antibodies (Darenberg et al., 2004; Schrage et al., 2006). Although there is no direct evidence to suggest SAg involvement, there also exists the Kawasaki-like syndrome, which in contrast to $\mathrm{KD}$ occurs primarily in adults with severe immunosuppression including HIV/AIDS (Stankovic et al., 2007).

\section{CHRONIC RHINOSINUSITIS}

Chronic rhinosinusitis (CRS) is a group of disorders characterized by inflammation of the nose and paranasal sinuses for at least 3 months duration (Van Crombruggen et al., 2011). CRS can occur with or without nasal polyps, and accumulated evidence is now convincing that $S$. aureus SAgs can contribute to, at least in some cases, CRS with nasal polyposis (Van Zele et al., 2004). In this disease, SAgs are thought to skew the cytokine response towards a $\mathrm{T}_{\mathrm{H}} 2$ phenotype inducing both eosinophilia and the production of polyclonal IgE, which in turn could be further linked to asthma (Bachert et al., 2010). There is no single SAg associated specifically to this disease (Van Zele et al., 2008; Heymans et al., 2010), and as noted (Van Crombruggen et al., 2011), a causal relationship with $S$. aureus has not been established.

\section{ATOPIC DERMATITIS}

Atopic dermatitis (AD) represents a chronic and relapsing T cell-mediated inflammatory skin disorder with IgE-mediated sensitization to allergens. AD most often affects infants and young children, but may persist into adulthood, or may first develop in adults as late-onset $\mathrm{AD}$. $\mathrm{AD}$ has both genetic and environmental contributions but nearly all AD patients are colonized by $S$. aureus. This is likely due to both the damaged skin barrier and impaired host immune responses. Significant evidence also indicates an important role for the staphylococcal SAgs in exacerbating the disease [reviewed in (Schlievert et al., 2010)]. SAgs have long been known to induce the skin homing receptor cutaneous lymphocyte-associated antigen (CLA) on T cells to recruit these cells to the skin (Leung et al., 1995a). Very recent evidence indicates that skin homing, phenotypically Treg (CD4+ FoxP3+) cells from $\mathrm{AD}$ patients may actually display a $\mathrm{T}_{\mathrm{H}} 2$ phenotype in response to SEB stimulation (Lin et al., 2011). AD patients may also develop anti-SAg IgE antibodies that can further worsen the condition (Leung et al., 1993; Bunikowski et al., 1999; Lin et al., 2000). AD is often treated with glucocorticoids and SAgs have been shown to induce glucocorticoid resistance in PBMCs (Hauk et al., 2000). A recent study that examined essentially the entire staphylococcal SAg family found that isolates from steroid resistant AD patients contained significantly more SAgs genes than isolates from non-steroid resistant patients or menstrual isolates provoking the idea that steroid treatment may actually select for SAgs in these strains (Schlievert et al., 2008).

\section{GUTTATE PSORIASIS}

Guttate psoriasis is an acute form of psoriasis mediated by autoreactive $\mathrm{T}$ cells that typically develops in young adults and children. This inflammatory skin disease is typically preceded by streptococcal pharyngitis, and the streptococcal SAgs, in particular SpeC, and $\mathrm{V} \beta 2^{+} \mathrm{T}$ cells have been implicated (Leung et al., 1995c). Some associations have also been made with $S$. aureus and chronic plaque psoriasis (Sayama et al., 1998; Balci et al., 2009).

\section{NASAL COLONIZATION AND STAPHYLOCOCCAL SUPERANTIGENS}

Staphylococcal colonization can be defined by the presence and multiplication of $S$. aureus in the absence of infection or disease. In humans, the anterior nares are the most common area colonized by $S$. aureus and the prevalence of nasal colonization is particularly high within the general population. Individuals have been typically classified into three separate groups based on their nasal carriage status: persistent, intermediate, or non-carriers. Approximately $20 \%$ of the general population are persistent carriers of $S$. aureus, $\sim 30 \%$ are intermittent carriers, and $\sim 50 \%$ are non-carriers (Wertheim et al., 2005). In the event of an infection, carriers have a better prognosis than non-carriers (von Eiff et al., 2001; Wertheim et al., 2004); however, nasal colonization increases the risk of infection by fourfold (Safdar and Bradley, 2008 ). Furthermore, it is believed that $\sim 80 \%$ of $S$. aureus bloodstream infections come from an endogenous source (von Eiff et al., 2001), and this can be particularly dangerous in a hospital setting if a nasal carrier is immunocompromised and the colonizing strain is resistant to antibiotics. 
Although a myriad of bacterial factors play a role in determining nasal colonization, it has not yet been established whether or not SAgs are involved. Epidemiological studies evaluating $S$. aureus SAg gene distribution in nasal swabs compared with blood isolates concluded that there were no differences between blood and nasal isolates in the number of toxins, or a correlation to a particular toxin and that toxin gene distribution was widespread and highly varied (Holtfreter et al., 2007). S. aureus strains encoding the same SAg genes can produce different amounts of toxin (Varshney et al., 2009) and this may make correlations difficult in epidemiological studies, which often rely on genomic typing instead of protein quantification.

The particular molecular switch by how colonized bacteria become pathogenic is likely a mixture of host-pathogen and environmental factors that leads to a breach in the mucosa and subsequent infection. The role of the two-component regulatory system $a g r$ has been classically associated with dissemination and the release of secretory proteins and downregulation of surface associated proteins (Recsei et al., 1986). Many SAgs such as TSST- 1 are regulated by agr (Recsei et al., 1986), which appears to be dampened during colonization, suggesting that agr-controlled SAgs may not be involved in colonization. This has been further supported where the constitutive expression of RNAIII, the effector molecule of the $a g r$ system, reduces nasal colonization in rats (Pynnonen et al., 2011). Thus, it is likely that agr is downregulated during colonization, which has been demonstrated in human studies (Burian et al., 2010). It has however, been suggested that certain SAgs such as staphylococcal enterotoxin A (SEA), which is not regulated by $a g r$, may play a role early on in colonization (Bohach and Schlievert, 2007). Although many persistent carriers contain the bacteriophage that carries SEA, this genetic element does not appear to play a role early on during colonization (Verkaik et al., 2011). Furthermore, the sea gene has been correlated with sepsis (Ferry et al., 2005), although the presence of SEA has yet to be confirmed in blood during sepsis. This work also demonstrated a correlation between the egc operon of SAgs and colonization (Ferry et al., 2005). A follow-up study using recombinant SAgs found that both types $(e g c$ and non-egc) of SAgs induced similar proliferative activity on PBMCs (Grumann et al., 2008). However, the proliferative potential of supernatants taken from patients with strains containing $e g c$ genes demonstrated that strains encoding egc SAgs do not have as high proliferative activity as strains encoding non-egc SAgs, suggesting that egc SAgs are not made in quantities as high as non-egc SAgs. A lack of neutralizing antibodies against $e g c$-encoded SAgs was also found in serum from healthy humans indicating either a lack of egc toxins being produced by $S$. aureus or an inability to produce neutralizing antibodies by the host (Holtfreter et al., 2004). It is interesting that only non-egc encoded SAgs have been implicated in toxin-mediated diseases. Thus, the role of egc-encoded SAgs in colonization requires further investigation.

It is difficult to directly ascertain whether or not SAgs are produced in vivo during colonization mainly due to the presence of $S$. aureus protein A, which binds the Fc portion of antibodies, thereby causing background levels of assays to be quite high. However, analysis of the immunological response can provide important information. In particular, both $\mathrm{V} \beta$-specific $\mathrm{T}$ cell activation and SAg-neutralizing antibodies are indirect ways of determining if SAgs have encountered the immune system. While $\mathrm{V} \beta$-skewing has been studied in the context of severe disease (Ferry et al., 2008b), it has long been known that the general population develops anti-SAg antibodies capable of neutralizing these toxins (Vergeront et al., 1983). Also, persistent nasal carriers of $S$. aureus have been found to have neutralizing antibodies against the SAgs produced by the colonizing strain (Holtfreter et al., 2006; Kolata et al., 2011). Levels of neutralizing antibodies against TSST-1 and SEA were significantly higher in persistent nasal carriers than non-carriers (Verkaik et al., 2009) suggesting that these SAgs are actively produced during nasal colonization.

To what extent, if any, do SAgs play during colonization has not yet been experimentally addressed. Intranasal vaccination in rodents with deactivated TSST-1 was able to decrease mortality rates from TSST-1 producing S. aureus septic challenge and significantly decreased the bacterial load in organs (Narita et al., 2008). This was a TSST- 1 specific response, as challenge with non-TSST-1 producing $S$. aureus did not result in a significant reduction in bacterial load when compared to non-vaccinated mice. The same vaccination strategy protected against nasal challenge only during the initial colonization phase (days 1 and 3). Since the model only evaluated colonization up to day 7 , it is difficult to assess whether or not this is able to have a lasting effect against $S$. aureus nasal persistence, since there were not significant effects at day 5 (Narita et al., 2008).

Staphylococcal peptidoglycan-embedded molecules have been found to downregulate the immune response stimulated by SAgs (Chau et al., 2009). This effect was most effective at high cell densities suggesting that it is important in a state of colonization or a biofilm as opposed to free-living planktonic cells. Thus, if a colonized population of $S$. aureus is producing SAgs, any invading "rogue" cells that are not a part of the main colony may be killed by an activated immune system, while the dense colony is able to downregulate this response in the local area to prevent clearance. This suggests a role for SAgs as checkpoints of dissemination. Evidence suggests that when SAgs are systemic in the case of TSS (Ferry et al., 2008b), S. aureus is able to prevent dissemination, which may be partly why bacteremia is rarely associated with staphylococcal TSS. This is also supported by the observation that sepsis patients lack V $\beta$-skewing unlike TSS patients (Ferry et al., 2008a), suggesting that bacterial dissemination prevents toxin production.

\section{FUTURE DIRECTIONS FOR RESEARCH}

The collective SAg research community has contributed enormously to an advanced understanding of SAg biology. Yet, there remain a number of important avenues for further study and consideration.

Although SAgs are defined by V $\beta$-specificity, different human MHC II molecules are also clearly important for the response to SAgs (Yeung et al., 1996; Medina et al., 2001; Kotb et al., 2002; Llewelyn et al., 2004; Goldmann et al., 2005; Nooh et al., 2007). Mouse models (such as $\mathrm{C} 57 \mathrm{BL} / 6$ and $\mathrm{BALBc}$ ) have been hampered by the fact that mouse MHC II do not respond in the same way, and are not as sensitive to SAgs, as human MHC (Yeung et al., 1996). Alternative models include rabbits that respond 
more appropriately (Parsonnet et al., 1987; Dinges and Schlievert, 2001; Buonpane et al., 2007), as well as transgenic mouse strains that express human MHC class II molecules (Yeung et al., 1996; DaSilva et al., 2002). Models of TSS also often utilize a liverdamaging reagent such as D-galactosamine in conjunction with high levels of SAgs. Liver and gut pathology has recently been implicated in the course of TSS in a humanized transgenic HLADR3 mouse model without the use of D-galactosamine (Tilahun et al., 2011a,b) and thus, D-galactosamine may mask pathologies normally induced via TSS. Lastly, although many studies using purified recombinant SAgs have yielded many insights, SAg function is still rarely studied in the context of live infections using genetically defined knockout strains. More work using live infections with appropriate SAg-responsive models is needed to be able to coordinate SAg production with other virulence factors.

Although a number of studies have evaluated the presence of S. aureus, and correlations of particular SAg genes with particular clinical syndromes, the presence of the gene does not equate to expression and function of the actual toxin. Indeed, the original discovery of TSST- 1 as the causal agent of menstrual TSS was made due to the high level production of this toxin from menstrual TSS strains (Bergdoll et al., 1981; Schlievert et al., 1981). For many human diseases where SAgs may contribute to, or drive the pathology, there is likely not being a single toxin responsible given that they can all activate numerous $\mathrm{T}$ cells. As we now know the $\mathrm{V} \beta$ skewing patterns of virtually all the known staphylococcal SAgs (Thomas et al., 2009; Seo et al., 2010; Wilson et al., 2011), further systematic evaluations focused on SAg expression coupled with function in relation to particular clinical syndromes (Ferry et al., 2008b), are warranted.

The large family of SAgs continue to grow, and the YPM and MAM SAgs seem to have developed their SAg-activity through convergent evolution as these toxins are not orthologous to the pyrogenic toxin SAgs, or to each other. Also, the animal model of KD utilizes an uncharacterized SAg from the cell wall preparation

\section{REFERENCES}

Abe, J., Kotzin, B. L., Jujo, K., Melish, M. E., Glode, M. P., Kohsaka, T., and Leung, D. Y. (1992). Selective expansion of $\mathrm{T}$ cells expressing $\mathrm{T}$-cell receptor variable regions $\mathrm{V}$ beta 2 and $\mathrm{V}$ beta 8 in Kawasaki disease. Proc. Natl. Acad. Sci. U.S.A. 89, 4066-4070.

Abrahmsen, L., Dohlsten, M., Segren, S., Bjork, P., Jonsson, E., and Kalland, T. (1995). Characterization of two distinct MHC class II binding sites in the superantigen staphylococcal enterotoxin A. EMBO J. 14, 2978-2986.

Arad, G., Levy, R., Nasie, I., Hillman, D., Rotfogel, Z., Barash, U., Supper, E., Shpilka, T., Minis, A., and Kaempfer, R. (2011). Binding of superantigen toxins into the CD28 homodimer interface is essential for induction of cytokine genes that mediate lethal shock. PLoS Biol. 9:e100-1149. doi: 10.1371/journal.pbio. 1001149
Argudin, M. A., Mendoza, M. C., and Rodicio, M. R. (2010). Food poisoning and Staphylococcus aureus enterotoxins. Toxins 2, 1751-1773.

Arvand, M., and Hahn, H. (1996). T-cell activation and proliferation in a case of recurrent menstrual toxic shock syndrome. Zentralbl. Bakteriol. 284, 164-169.

Bachert, C., Zhang, N., Holtappels, G., De Lobel, L., Van Cauwenberge, P., Liu, S., Lin, P., Bousquet, J., and Van Steen, K. (2010). Presence of IL-5 protein and IgE antibodies to staphylococcal enterotoxins in nasal polyps is associated with comorbid asthma. J. Allergy Clin. Immunol. 126, 962-968, 968 e961-966.

Baker, H. M., Basu, I., Chung, M. C., Caradoc-Davies, T., Fraser, J. D., and Baker, E. N. (2007). Crystal structures of the staphylococcal toxin SSL5 in complex with sialyl Lewis $\mathrm{X}$ reveal a conserved binding site that shares common features with

of Lactobacillus casei to induce the disease in mice (Yeung, 2007). L. case $i$ is found commonly in the intestinal tract, is widely used by the dairy industry, and is clearly not a pathogen. It is easy to speculate that uncharacterized SAgs could be produced by other microorganisms associated with human immune mediated sequelae.

Arguably the most interesting question that remains in this field is why do S. aureus possess such a large, genetically and antigenically distinct, extremely potent, and seemingly redundant group of these toxins? SAgs skew responses toward $\mathrm{T}_{\mathrm{H}} 1$ during severe disease, but toward $\mathrm{T}_{\mathrm{H}} 2$ responses during atopic disease in genetically predisposed individuals. $\mathrm{T}_{\mathrm{H}} 1$ skewing can result in delayed development of neutralizing antibody and perhaps this is an important in vivo survival strategy. Many patients following menstrual TSS fail to develop anti-TSST- 1 antibodies (Stolz et al., 1985) so this can occur from TSS. Conversely, humans clearly develop anti-TSST- 1 antibodies such that by age 1, 50\% have antibody titers considered to be protective (Vergeront et al., 1983). An interesting hypothesis has been proposed where excessive $\mathrm{T}$ cell expansion may act as a sponge to titrate IL-2 necessary for further $\mathrm{T}$ cell expansion, essentially causing immunosuppression (Llewelyn and Cohen, 2002). Similarly, massive expansion of $\mathrm{V} \beta$-specific T cells may induce a loss of overall receptor diversity filling up the "space," providing an alternative method of immune escape. Continued efforts into understanding the complex biology of SAgs will undoubtedly answer many of these questions. It is clear that these remarkable toxins represent a highly unique and well adapted virulence factor, although the evolutionary function of these toxin in the life cycle of $S$. aureus still remains unclear.

\section{ACKNOWLEDGMENTS}

Research on bacterial superantigens in the McCormick laboratory is supported by operating funds from the Canadian Institutes of Health Research. Stacey X. Xu is supported by a Queen Elizabeth II Graduate Scholarship in Science and Technology.

viral and bacterial sialic acid binding proteins. J. Mol. Biol. 374, 1298-1308.

Balci, D. D., Duran, N., Ozer, B., Gunesacar, R., Onlen, Y., and Yenin, J. Z. (2009). High prevalence of Staphylococcus aureus cultivation and superantigen production in patients with psoriasis. Eur. J. Dermatol. 19, 238-242.

Bergdoll, M. S., Crass, B. A., Reiser, R. F., Robbins, R. N., and Davis, J. P. (1981). A new staphylococcal enterotoxin, enterotoxin $\mathrm{F}$, associated with toxic- shock-syndrome Staphylococcus aureus isolates. Lancet 1, 1017-1021.

Bohach, G. A., Fast, D. J., Nelson, R. D., and Schlievert, P. M. (1990). Staphylococcal and streptococcal pyrogenic toxins involved in toxic shock syndrome and related illnesses. Crit. Rev. Microbiol. 17, 251-272.
Bohach, G., and Schlievert, P. M (2007). "Staphylococcal and streptococcal superantigens: an update," in Superantigens: Molecular Basis for the Role in Human Diseases, eds J. D. Fraser and M. Kotb (Washington, DC: ASM Press), 21-36.

Bueno, C., Criado, G., McCormick, J. K., and Madrenas, J. (2007). $\mathrm{T}$ cell signalling induced by bacterial superantigens. Chem. Immunol. Allergy 93, 161-180.

Bueno, C., Lemke, C. D., Criado, G., Baroja, M. L., Ferguson, S. S., Rahman, A. K., Tsoukas, C. D., McCormick, J. K., and Madrenas, J. (2006). Bacterial superantigens bypass Lck-dependent $\mathrm{T}$ cell receptor signaling by activating a Galpha11-dependent, PLC-betamediated pathway. Immunity 25 , 67-78.

Bunikowski, R., Mielke, M., Skarabis, H., Herz, U., Bergmann, R. L., Wahn, U., and Renz, H. (1999). 
Prevalence and role of serum $\operatorname{IgE}$ antibodies to the Staphylococcus aureus-derived superantigens SEA and SEB in children with atopic dermatitis. J. Allergy Clin. Immunol. 103, 119-124.

Buonpane, R. A., Churchill, H. R. Moza, B., Sundberg, E. J., Peterson, M. L., Schlievert, P. M., and Kranz, D. M. (2007). Neutralization of staphylococcal enterotoxin B by soluble, high-affinity receptor antagonists. Nat. Med. 13, 725-729.

Burian, M., Rautenberg, M., Kohler, T., Fritz, M., Krismer, B., Unger, C., Hoffmann, W. H., Peschel, A., Wolz, C., and Goerke, C. (2010). Temporal expression of adhesion factors and activity of global regulators during establishment of Staphylococcus aureus nasal colonization. J. Infect. Dis. 201, 1414-1421.

Centers for Disease Control and Prevention. (2011). Toxic Shock Syndrome; 2011 Case Definition.

Chau, T. A., McCully, M. L., Brintnell, W., An, G., Kasper, K. J., Vines, E. D., Kubes, P., Haeryfar, S. M., McCormick, J. K., Cairns, E., Heinrichs, D. E., and Madrenas, J. (2009). Toll-like receptor 2 ligands on the staphylococcal cell wall downregulate superantigeninduced $\mathrm{T}$ cell activation and prevent toxic shock syndrome. Nat. Med. 15, 641-648.

Choi, Y. W., Kotzin, B., Herron, L., Callahan, J., Marrack, P., and Kappler, J. (1989). Interaction of Staphylococcus aureus toxin "superantigens" with human $\mathrm{T}$ cells. Proc. Natl. Acad. Sci. U.S.A. 86, 8941-8945.

Chung, M. C., Wines, B. D., Baker, H., Langley, R. J., Baker, E. N., and Fraser, J. D. (2007). The crystal structure of staphylococcal superantigen-like protein 11 in complex with sialyl Lewis $\mathrm{X}$ reveals the mechanism for cell binding and immune inhibition. Mol. Microbiol. 66, 1342-1355.

Dack, G. M., Cary, W. E., Woolpert, O., and Wiggers, H. (1930). An outbreak of food poisoning proved to be due to a yellow hemolytic staphylococcus. J. Prev. Med. 4, 167-175.

Darenberg, J., Soderquist, B., Normark, B. H., and Norrby-Teglund, A. (2004). Differences in potency of intravenous polyspecific immunoglobulin $\mathrm{G}$ against streptococcal and staphylococcal superantigens: implications for therapy of toxic shock syndrome. Clin. Infect. Dis. 38, 836-842.

DaSilva, L., Welcher, B. C., Ulrich, R. G., Aman, M. J., David, C. S., and Bavari, S. (2002). Humanlike immune response of human leukocyte antigen-DR3 transgenic mice to staphylococcal enterotoxins: a novel model for superantigen vaccines. $J$. Infect. Dis. 185, 1754-1760.

DeVries, A. S., Lesher, L., Schlievert, P. M., Rogers, T., Villaume, L. G., Danila, R., and Lynfield, R. (2011). Staphylococcal toxic shock syndrome 2000-2006: epidemiology, clinical features, and molecular characteristics. PLoS One 6:e22997. doi: 10.1371/journal.pone.0022997

Dinges, M. M., and Schlievert, P. M. (2001). Comparative analysis of lipopolysaccharide-induced tumor necrosis factor alpha activity in serum and lethality in mice and rabbits pretreated with the staphylococcal superantigen toxic shock syndrome toxin 1. Infect. Immun. 69, 7169-7172.

Fernandez, M. M., Guan, R., Swaminathan, C. P., Malchiodi, E. L., and Mariuzza, R. A. (2006). Crystal structure of staphylococcal enterotoxin I (SEI) in complex with a human major histocompatibility complex class II molecule. J. Biol. Chem. 281, 25356-25364.

Ferry, T., Thomas, D., Bouchut, J. C., Lina, G., Vasselon-Raina, M., Dauwalder, O., Gillet, Y., Vandenesch, F., Floret, D., and Etienne, J. (2008a). Early diagnosis of staphylococcal toxic shock syndrome by detection of the TSST-1 Vbeta signature in peripheral blood of a 12-year-old boy. Pediatr. Infect. Dis. J. 27, 274-277.

Ferry, T., Thomas, D., Genestier, A. L., Bes, M., Lina, G., Vandenesch, F., and Etienne, J. (2005). Comparative prevalence of superantigen genes in Staphylococcus aureus isolates causing sepsis with and without septic shock. Clin. Infect. Dis. 41, 771-777.

Ferry, T., Thomas, D., Perpoint, T., Lina, G., Monneret, G., Mohammedi, I., Chidiac, C., Peyramond, D., Vandenesch, F., and Etienne, J. (2008b). Analysis of superantigenic toxin Vbeta T-cell signatures produced during cases of staphylococcal toxic shock syndrome and septic shock. Clin. Microbiol. Infect. 14, 546-554.

Fields, B. A., Malchiodi, E. L., Li, H., Ysern, X., Stauffacher, C. V., Schlievert, P. M., Karjalainen, K., and Mariuzza, R. A. (1996). Crystal structure of a T-cell receptor betachain complexed with a superantigen. Nature 384, 188-192.

Fuller, C. L., and Braciale, V. L. (1998). Selective induction of CD8+ cytotoxic $\mathrm{T}$ lymphocyte effector function by staphylococcus enterotoxin B. J. Immunol. 161, 5179-5186.
Garcia, K. C., and Adams, E. J. (2005). How the T cell receptor sees antigen-a structural view. Cell 122, 333-336.

Garcia, K. C., Teyton, L., and Wilson, I. A. (1999). Structural basis of T cell recognition. Annu. Rev. Immunol. 17, 369-397.

Gaventa, S., Reingold, A. L., Hightower, A. W., Broome, C. V., Schwartz, B., Hoppe, C., Harwell, J., Lefkowitz, L. K., Makintubee, S., Cundiff, D. R., Sitze, S., and Toxic Shock Syndrome Study Group. (1989). Active surveillance for toxic shock syndrome in the United States, 1986. Rev. Infect. Dis. 11 (Suppl. 1), S28-S34.

Givan, A. L., Fisher, J. L., Waugh, M., Ernstoff, M. S., and Wallace, P. K. (1999). A flow cytometric method to estimate the precursor frequencies of cells proliferating in response to specific antigens. J. Immunol. Methods 230, 99-112.

Goldmann, O., Lengeling, A., Bose, J., Bloecker, H., Geffers, R., Chhatwal, G. S., and Medina, E. (2005). The role of the MHC on resistance to group a streptococci in mice. $J$. Immunol. 175, 3862-3872.

Grumann, D., Scharf, S. S., Holtfreter, S., Kohler, C., Steil, L., Engelmann S., Hecker, M., Volker, U., and Broker, B. M. (2008). Immune cell activation by enterotoxin gene cluster (egc)-encoded and non-egc superantigens from Staphylococcus aureus. I. Immunol. 181, 5054-5061.

Gunther, S., Varma, A. K., Moza, B., Kasper, K. J., Wyatt, A. W., Zhu, P., Rahman, A. K., Li, Y., Mariuzza, R. A., McCormick, J. K., and Sundberg, E. J. (2007). A novel loop domain in superantigens extends their $\mathrm{T}$ cell receptor recognition site. J. Mol. Biol. 371, 210-221.

Hauk, P. J., Hamid, Q. A., Chrousos, G. P., and Leung, D. Y. (2000) Induction of corticosteroid insensitivity in human PBMCs by microbial superantigens. J. Allergy Clin. Immunol. 105, 782-787.

Heeg, K., Gaus, H., Griese, D., Bendigs, S., Miethke, T., and Wagner, $\mathrm{H}$ (1995). Superantigen-reactive $T$ cells that display an anergic phenotype in vitro appear functional in vivo. Int Immunol. 7, 105-114.

Hennecke, J., Carfi, A., and Wiley, D. C. (2000). Structure of a covalently stabilized complex of a human alphabeta T-cell receptor, influenza HA peptide and MHC class II molecule, HLA-DR1. EMBO J. 19, 5611-5624.

Hennekinne, J. A., De Buyser, M. L., and Dragacci, S. (2011). Staphylococcus aureus and its food poisoning toxins: characterization and outbreak investigation. FEMS
Microbiol. Rev. doi: 10.1111/j.15746976.2011.00311.x. [Epub ahead of print].

Herrmann, T., Baschieri, S., Lees, R. K., and Macdonald, H. R. (1992). In vivo responses of $\mathrm{CD} 4+$ and CD8+ cells to bacterial superantigens. Eur. J. Immunol. 22, 1935-1938.

Heymans, F., Fischer, A., Stow, N. W., Girard, M., Vourexakis, Z., Des Courtis, A., Renzi, G., Huggler, E., Vlaminck, S., Bonfils, P., Mladina, R., Lund, V., Schrenzel, J., Francois, P., and Lacroix, J. S. (2010). Screening for staphylococcal superantigen genes shows no correlation with the presence or the severity of chronic rhinosinusitis and nasal polyposis. PLoS One 5:e9525. doi: 10.1371/journal.pone.0009525

Holtfreter, S., Bauer, K., Thomas, D., Feig, C., Lorenz, V., Roschack, K., Friebe, E., Selleng, K., Lovenich, S., Greve, T., Greinacher, A., Panzig, B., Engelmann, S., Lina, G., and Broker, B. M. (2004). egc-Encoded superantigens from Staphylococcus aureus are neutralized by human sera much less efficiently than are classical staphylococcal enterotoxins or toxic shock syndrome toxin Infect. Immun. 72, 4061-4071.

Holtfreter, S., Grumann, D., Schmudde, M., Nguyen, H. T., Eichler, P., Strommenger, B., Kopron, K., Kolata, J., Giedrys-Kalemba, S., Steinmetz, I., Witte, W., and Broker, B. M. (2007). Clonal distribution of superantigen genes in clinical Staphylococcus aureus isolates. J. Clin. Microbiol. 45, 2669-2680.

Holtfreter, S., Roschack, K., Eichler, P., Eske, K., Holtfreter, B., Kohler, C., Engelmann, S., Hecker, M., Greinacher, A., and Broker, B. M. (2006). Staphylococcus aureus carriers neutralize superantigens by antibodies specific for their colonizing strain: a potential explanation for their improved prognosis in severe sepsis. J. Infect. Dis. 193, 1275-1278. Hovde, C. J., Marr, J. C., Hoffmann, M. L., Hackett, S. P., Chi, Y. I., Crum, K. K., Stevens, D. L., Stauffacher, C. V., and Bohach, G. A. (1994). Investigation of the role of the disulphide bond in the activity and structure of staphylococcal enterotoxin C1. Mol. Microbiol. 13, 897-909.

Hudson, K. R., Tiedemann, R. E., Urban, R. G., Lowe, S. C., Strominger, J. L., and Fraser, J. D. (1995) Staphylococcal enterotoxin A has two cooperative binding sites on major histocompatibility complex class II. J. Exp. Med. 182, 711-720. Jardetzky, T. S., Brown, J. H., Gorga, J. C., Stern, L. J., Urban, R. G., Chi, 
Y. I., Stauffacher, C., Strominger, J. L., and Wiley, D. C. (1994). Three-dimensional structure of a human class II histocompatibility molecule complexed with superantigen. Nature 368, 711-718.

Jordan, E. O. (1930). The production by staphylococci of a substance causing food poisoning. JAMA 94, $1648-1650$.

Kasper, K. J., Xi, W., Rahman, A. K., Nooh, M. M., Kotb, M., Sundberg, E. J., Madrenas, J., and McCormick, J. K. (2008). Molecular requirements for MHC class II alpha-chain engagement and allelic discrimination by the bacterial superantigen streptococcal pyrogenic exotoxin C. J. Immunol. 181, 3384-3392.

Kawabe, Y., and Ochi, A. (1990). Selective anergy of $\mathrm{V}$ beta $8+$, CD4+ $\mathrm{T}$ cells in Staphylococcus enterotoxin B-primed mice. J. Exp. Med. 172, 1065-1070.

Kim, J., Urban, R. G., Strominger, J. L., and Wiley, D. C. (1994). Toxic shock syndrome toxin-1 complexed with a class II major histocompatibility molecule HLA-DR1. Science 266, 1870-1874.

Kissner, T. L., Ruthel, G., Alam, S., Ulrich, R. G., Fernandez, S., and Saikh, K. U. (2011). Activation of MyD88 signaling upon staphylococcal enterotoxin binding to MHC class II molecules. PLoS One 6:e15985. doi: 10.1371/journal.pone.0015985

Kolata, J., Bode, L. G., Holtfreter, S., Steil, L., Kusch, H., Holtfreter, B., Albrecht, D., Hecker, M., Engelmann, S., Van Belkum, A., Volker, U., and Broker, B. M. (2011). Distinctive patterns in the human antibody response to Staphylococcus aureus bacteremia in carriers and non-carriers. Proteomics 11, 3914-3927.

Kotb, M., Norrby-Teglund, A., McGeer, A., El-Sherbini, H., Dorak, M. T., Khurshid, A., Green, K., Peeples, J., Wade, J., Thomson, G., Schwartz, B., and Low, D. E. (2002). An immunogenetic and molecular basis for differences in outcomes of invasive group A streptococcal infections. Nat. Med. 8, 1398-1404.

Langley, R., Patel, D., Jackson, N., Clow, F., and Fraser, J. D. (2010). Staphylococcal superantigen superdomains in immune evasion. Crit. Rev. Immunol. 30, 149-165.

Lee, W. T., and Vitetta, E. S. (1992). Memory $\mathrm{T}$ cells are anergic to the superantigen staphylococcal enterotoxin B. J. Exp. Med. 176, 575-579.

Leung, D. Y., Gately, M., Trumble, A., Ferguson-Darnell, B., Schlievert, P. M., and Picker, L. J. (1995a). Bacterial superantigens induce $\mathrm{T}$ cell expression of the skin-selective homing receptor, the cutaneous lymphocyteassociated antigen, via stimulation of interleukin 12 production. J. Exp. Med. 181, 747-753.

Leung, D. Y., Harbeck, R., Bina, P., Reiser, R. F., Yang, E., Norris, D. A., Hanifin, J. M., and Sampson, H. A. (1993). Presence of IgE antibodies to staphylococcal exotoxins on the skin of patients with atopic dermatitis. Evidence for a new group of allergens. J. Clin. Invest. 92, 1374-1380.

Leung, D. Y., Meissner, C., Fulton, D., and Schlievert, P. M. (1995b). The potential role of bacterial superantigens in the pathogenesis of Kawasaki syndrome. J. Clin. Immunol. 15, 11S-17S.

Leung, D. Y., Travers, J. B., Giorno, R., Norris, D. A., Skinner, R., Aelion, J., Kazemi, L. V., Kim, M. H., Trumble, A. E., and Kotb, M. (1995c). Evidence for a streptococcal superantigen-driven process in acute guttate psoriasis. J. Clin. Invest. 96, 2106-2112.

Li, H., Llera, A., Malchiodi, E. L., and Mariuzza, R. A. (1999). The structural basis of $\mathrm{T}$ cell activation by superantigens. Annu. Rev. Immunol. 17, 435-466.

Li, H., Llera, A., Tsuchiya, D., Leder, L., Ysern, X., Schlievert, P. M., Karjalainen, K., and Mariuzza, R. A. (1998). Three-dimensional structure of the complex between a $\mathrm{T}$ cell receptor beta chain and the superantigen staphylococcal enterotoxin B. Immunity 9, 807-816.

Li, Y., Li, H., Dimasi, N., McCormick, J. K., Martin, R., Schuck, P., Schlievert, P. M., and Mariuzza, R. A. (2001). Crystal structure of a superantigen bound to the high-affinity, zincdependent site on MHC class II. Immunity 14, 93-104.

Lin, Y. T., Shau, W. Y., Wang, L. F., Yang, Y. H., Hwang, Y. W., Tsai, M. J., Tsao, P. N., and Chiang, B. L. (2000). Comparison of serum specific IgE antibodies to staphylococcal enterotoxins between atopic children with and without atopic dermatitis. Allergy 55, 641-646.

Lin, Y. T., Wang, C. T., Chao, P. S., Lee, J. H., Wang, L. C., Yu, H. H., Yang, Y. H., and Chiang, B. L. (2011). Skin-homing CD4+ Foxp3+ T cells exert Th2-like function after staphylococcal superantigen stimulation in atopic dermatitis patients. Clin. Exp. Allergy 41, 516-525.

Lina, G., Bohach, G. A., Nair, S. P., Hiramatsu, K., Jouvin-Marche, E., and Mariuzza, R. (2004). Standard nomenclature for the superantigens expressed by Staphylococcus. J. Infect. Dis. 189, 2334-2336.

Llewelyn, M., and Cohen, J. (2002). Superantigens: microbial agents that corrupt immunity. Lancet Infect. Dis. 2, 156-162.

Llewelyn, M., Sriskandan, S., Peakman, M., Ambrozak, D. R., Douek, D. C., Kwok, W. W., Cohen, J. and Altmann, D. M. (2004). HLA class II polymorphisms determine responses to bacterial superantigens. J. Immunol. 172, 1719-1726.

Marrack, P., and Kappler, J. (1990). The staphylococcal enterotoxins and their relatives. Science 248, 705-711.

Matsubara, K., and Fukaya, T. (2007) The role of superantigens of group A Streptococcus and Staphylococcus aureus in Kawasaki disease. Curr. Opin. Infect. Dis. 20, 298-303.

McCormick, J. K., Yarwood, J. M., and Schlievert, P. M. (2001). Toxic shock syndrome and bacterial superantigens: an update. Аnпu. Rev. Microbiol. 55, 77-104.

McGavin, M. J., Arsic, B., and Nickerson, N. N. (2012). Evolutionary blueprin for host- and niche-adaptation in Staphylococcus aureus clonal complex CC30. Front. Cell. Inf. Microbio. 2: 48. doi: 10.3389/fcimb.2012.00048

Medina, E., Goldmann, O., Rohde, M. Lengeling, A., and Chhatwal, G. S. (2001). Genetic control of susceptibility to group A streptococcal infection in mice. J. Infect. Dis. 184 846-852.

Miller, C., Ragheb, J. A., and Schwartz, R. H. (1999). Anergy and cytokinemediated suppression as distinct superantigen-induced tolerance mechanisms in vivo. J. Exp. Med. 190, 53-64

Mitchell, D. T., Levitt, D. G., Schlievert, P. M., and Ohlendorf, D. H. (2000). Structural evidence for the evolution of pyrogenic toxin superantigens. J. Mol. Evol. 51, 520-531.

Morgan, M. M., Labno, C. M., Van Seventer, G. A., Denny, M. F., Straus, D. B., and Burkhardt, J. K. (2001) Superantigen-induced $\mathrm{T}$ cell:B cell conjugation is mediated by LFA-1 and requires signaling through Lck, but not ZAP-70. J. Immunol. 167, 5708-5718.

Moza, B., Buonpane, R. A., Zhu, P., Herfst, C. A., Rahman, A. K. McCormick, J. K., Kranz, D. M. and Sundberg, E. J. (2006). Longrange cooperative binding effects in a $\mathrm{T}$ cell receptor variable domain. Proc. Natl. Acad. Sci. U.S.A. 103, 9867-9872.

Moza, B., Varma, A. K., Buonpane, R. A., Zhu, P., Herfst, C. A., Nicholson,
M. J., Wilbuer, A.-K., Seth, N. P., Wucherpfennig, K. W., McCormick, J. K., Kranz, D. M., and Sundberg, E. J. (2007). Structural basis of T-cell specificity and activation by the bacterial superantigen TSST-1. EMBO J. 26, 1187-1197.

Munson, S. H., Tremaine, M. T., Betley, M. J., and Welch, R. A. (1998). Identification and characterization of staphylococcal enterotoxin types $\mathrm{G}$ and I from Staphylococcus aureus. Infect. Immun. 66, 3337-3348.

Narita, K., Hu, D. L., Tsuji, T., and Nakane, A. (2008). Intranasal immunization of mutant toxic shock syndrome toxin 1 elicits systemic and mucosal immune response against Staphylococcus aureus infection. FEMS Immunol. Med. Microbiol. 52, 389-396.

Newburger, J. W., Takahashi, M., Burns, J. C., Beiser, A. S., Chung, K. J., Duffy, C. E., Glode, M. P., Mason, W. H., Reddy, V., Sanders, S. P., Shulman, S. T., Wiggins, J. W. Hicks, R. V., Fulton, D. R., Lewis, A. B., Leung, D. Y. M., Colton, T., Rosen, F. S., and Melish, M. E. (1986). The treatment of Kawasaki syndrome with intravenous gamma globulin. N. Engl. J. Med. 315, 341-347.

Nizet, V. (2007). Understanding how leading bacterial pathogens subvert innate immunity to reveal novel therapeutic targets. J. Allergy Clin. Immunol. 120, 13-22.

Nomura, Y., Masuda, K., Shinkoda, Y., Sameshima, K., Oku, S., Yoshinaga, M., and Miyata, K. (1998). Twentyfive types of T-cell receptor Vbeta family repertoire in patients with Kawasaki syndrome. Eur. J. Pediatr. 157, 981-986.

Nooh, M. M., El-Gengehi, N., Kansal, R., David, C. S., and Kotb, M. (2007). HLA transgenic mice provide evidence for a direct and dominant role of HLA class II variation in modulating the severity of streptococcal sepsis. J. Immunol. 178, 3076-3083.

Osterholm, M. T., and Forfang, J. C. (1982). Toxic-shock syndrome in Minnesota: results of an activepassive surveillance system. J. Infect. Dis. 145, 458-464.

Parsonnet, J., Gillis, Z. A., Richter, A. G., and Pier, G. B. (1987). A rabbit model of toxic shock syndrome that uses a constant, subcutaneous infusion of toxic shock syndrome toxin 1. Infect. Immun. 55, 1070-1076.

Petersson, K., Hakansson, M., Nilsson, H., Forsberg, G., Svensson, L. A., Liljas, A., and Walse, B. (2001) Crystal structure of a superantigen 
bound to MHC class II displays zinc and peptide dependence. $E M B O \mathrm{~J}$. 20, 3306-3312.

Petersson, K., Pettersson, H., Skartved, N. J., Walse, B., and Forsberg, G. (2003). Staphylococcal enterotoxin $\mathrm{H}$ induces $\mathrm{V}$ alpha-specific expansion of $\mathrm{T}$ cells. J. Immunol. $170,4148-4154$.

Petersson, K., Thunnissen, M., Forsberg, G., and Walse, B. (2002). Crystal structure of a SEA variant in complex with MHC class II reveals the ability of SEA to crosslink MHC molecules. Structure 10, 1619-1626.

Proft, T., and Fraser, J. D. (2003). Bacterial superantigens. Clin. Exp. Immunol. 133, 299-306.

Pumphrey, N., Vuidepot, A., Jakobsen, B., Forsberg, G., Walse, B., and Lindkvist-Petersson, K. (2007). Cutting edge: evidence of direct TCR alpha-chain interaction with superantigen. J. Immunol. 179, 2700-2704.

Pynnonen, M., Stephenson, R. E., Schwartz, K., Hernandez, M., and Boles, B. R. (2011). Hemoglobin promotes Staphylococcus aureus nasal colonization. PLoS Pathog. 7:e1002104. doi: 10.1371/journal. ppat.1002104

Rahman, A. K., Bonsor, D. A., Herfst, C. A., Pollard, F., Peirce, M., Wyatt, A. W., Kasper, K. J., Madrenas, J., Sundberg, E. J., and McCormick, J. K. (2011). The $\mathrm{T}$ cell receptor beta-chain second complementarity determining region loop (CDR2beta) governs $\mathrm{T}$ cell activation and Vbeta specificity by bacterial superantigens. J. Biol. Chem. 286, 4871-4881.

Ramsland, P. A., Willoughby, N., Trist, H. M., Farrugia, W., Hogarth, P. M., Fraser, J. D., and Wines, B. D. (2007). Structural basis for evasion of IgA immunity by Staphylococcus aureus revealed in the complex of SSL7 with Fc of human IgA1. Proc. Natl. Acad. Sci. U.S.A. 104, 15051-15056.

Rasigade, J. P., Thomas, D., Perpoint, T., Peyramond, D., Chidiac, C., Etienne, J., Vandenesch, F., Lina, G., and Ferry, T. (2011). T-cell response to superantigen restimulation during menstrual toxic shock syndrome. FEMS Immunol. Med. Microbiol. 62, 368-371.

Recsei, P., Kreiswirth, B., O'Reilly, M., Schlievert, P., Gruss, A., and Novick, R. P. (1986). Regulation of exoprotein gene expression in Staphylococcus aureus by agr. Mol. Gen. Genet. 202, 58-61.

Rellahan, B. L., Jones, L. A., Kruisbeek, A. M., Fry, A. M., and Matis, L. A.
(1990). In vivo induction of anergy in peripheral $\mathrm{V}$ beta $8+\mathrm{T}$ cells by staphylococcal enterotoxin B. J. Exp. Med. 172, 1091-1100.

Safdar, N., and Bradley, E. A. (2008). The risk of infection after nasal colonization with Staphylococcus aureus. Am. J. Med. 121, 310-315.

Saline, M., Rodstrom, K. E., Fischer, G., Orekhov, V. Y., Karlsson, B. G., and Lindkvist-Petersson, K. (2010). The structure of superantigen complexed with TCR and MHC reveals novel insights into superantigenic T cell activation. Nat. Commun. 1, 119.

Sayama, K., Midorikawa, K., Hanakawa, Y., Sugai, M., and Hashimoto, K. (1998). Superantigen production by Staphylococcus aureus in psoriasis. Dermatology 196, 194-198.

Schlievert, P. M. (1986). Staphylococcal enterotoxin B and toxic-shock syndrome toxin- 1 are significantly associated with non-menstrual TSS [letter]. Lancet 1, 1149-1150.

Schlievert, P. M., Case, L. C., Strandberg, K. L., Abrams, B. B., and Leung, D. Y. (2008). Superantigen profile of Staphylococcus aureus isolates from patients with steroidresistant atopic dermatitis. Clin. Infect. Dis. 46, 1562-1567.

Schlievert, P. M., Jablonski, L. M., Roggiani, M., Sadler, I., Callantine, S., Mitchell, D. T., Ohlendorf, D. H., and Bohach, G. A. (2000). Pyrogenic toxin superantigen site specificity in toxic shock syndrome and food poisoning in animals. Infect. Immun. 68, 3630-3634.

Schlievert, P. M., Shands, K. N., Dan, B. B., Schmid, G. P., and Nishimura, R. D. (1981). Identification and characterization of an exotoxin from Staphylococcus aureus associated with toxic-shock syndrome. J. Infect. Dis. 143, 509-516.

Schlievert, P. M., Strandberg, K. L., Lin, Y. C., Peterson, M. L., and Leung, D. Y. (2010). Secreted virulence factor comparison between methicillinresistant and methicillin-sensitive Staphylococcus aureus, and its relevance to atopic dermatitis. J. Allergy Clin. Immunol. 125, 39-49.

Schrage, B., Duan, G., Yang, L. P., Fraser, J. D., and Proft, T. (2006). Different preparations of intravenous immunoglobulin vary in their efficacy to neutralize streptococcal superantigens: implications for treatment of streptococcal toxic shock syndrome. Clin. Infect. Dis. $43,743-746$.
Seo, K. S., Park, J. Y., Terman, D. S., and Bohach, G. A. (2010). A quantitative real time PCR method to analyze $\mathrm{T}$ cell receptor Vbeta subgroup expansion by staphylococcal superantigens. J. Transl. Med. 8, 2.

Shands, K. N., Schmid, G. P., Dan, B. B., Blum, D., Guidotti, R. J., Hargrett, N. T., Anderson, R. L., Hill, D. L. Broome, C. V., Band, J. D., and Fraser, D. W. (1980). Toxic-shock syndrome in menstruating women: association with tampon use and Staphylococcus aureus and clinical features in 52 cases. N. Engl. J. Med. 303, 1436-1442.

Smith-Garvin, J. E., Koretzky, G. A. and Jordan, M. S. (2009). T cell activation. Annu. Rev. Immunol. 27, 591-619.

Stankovic, K., Miailhes, P., Bessis, D., Ferry, T., Broussolle, C., and Seve, P. (2007). Kawasaki-like syndromes in HIV-infected adults. J. Infect. 55, 488-494.

Stevens, D. L., Tanner, M. H., Winship, J., Swarts, R., Ries, K. M., Schlievert, P. M., and Kaplan, E. (1989). Severe group A streptococcal infections associated with a toxic shock- like syndrome and scarlet fever toxin A. N. Engl. J. Med. 321, 1-7.

Stevens, F. A. (1927). The occurence of Staphylococcus aureus infection with a scarlitiniform rash. JAMA 88 , 1957-1958.

Stolz, S. J., Davis, J. P., Vergeront, J. M., Crass, B. A., Chesney, P. J., Wand, P. J., and Bergdoll, M. S. (1985). Development of serum antibody to toxic shock toxin among individuals with toxic shock syndrome in Wisconsin. J. Infect. Dis. 151, 883-889.

Sundberg, E. J., Li, H., Llera, A S., McCormick, J. K., Tormo, J. Schlievert, P. M., Karjalainen, K., and Mariuzza, R. A. (2002) Structures of two streptococcal superantigens bound to TCR beta chains reveal diversity in the architecture of $\mathrm{T}$ cell signaling complexes. Structure 10, 687-699.

Swietnicki, W., Barnie, A. M., Dyas, B. K., and Ulrich, R. G. (2003) Zinc binding and dimerization of Streptococcus pyogenes pyrogenic exotoxin $\mathrm{C}$ are not essential for T-cell stimulation. J. Biol. Chem. 278, 9885-9895.

Taylor, A. L., and Llewelyn, M. J. (2010). Superantigen-induced proliferation of human CD4+CD25- T cells is followed by a switch to a functional regulatory phenotype. J. Immunol. 185, 6591-6598.

Thomas, D., Dauwalder, O., Brun, V., Badiou, C., Ferry, T., Etienne, J., Vandenesch, F., and Lina, G.
(2009). Staphylococcus aureus superantigens elicit redundant and extensive human Vbeta patterns. Infect. Immun. 77, 2043-2050.

Tilahun, A. Y., Holz, M., Wu, T. T., David, C. S., and Rajagopalan, G. (2011a). Interferon gammadependent intestinal pathology contributes to the lethality in bacterial superantigen-induced toxic shock syndrome. PLoS One 6:e16764. doi: 10.1371/journal. pone. 0016764

Tilahun, A. Y., Marietta, E. V., Wu, T. T., Patel, R., David, C. S., and Rajagopalan, G. (2011b). Human leukocyte antigen class II transgenic mouse model unmasks the significant extrahepatic pathology in toxic shock syndrome. Am. J. Pathol. 178, 2760-2773.

Todd, J. K., Kapral, F. A., Fishaut, M., and Welch, T. R. (1978). Toxic shock syndrome associated with phage group 1 staphylococci. Lancet 2, 1116-1118.

Tripp, T. J., McCormick, J. K., Webb J. M., and Schlievert, P. M. (2003). The zinc-dependent major histocompatibility complex class II binding site of streptococcal pyrogenic exotoxin $\mathrm{C}$ is critical for maximal superantigen function and toxic activity. Infect. Immun. 71, 1548-1550.

Van Crombruggen, K., Zhang, N., Gevaert, P., Tomassen, P., and Bachert, C. (2011). Pathogenesis of chronic rhinosinusitis: inflammation. J. Allergy Clin. Immunol. 128, 728-732.

Van Zele, T., Gevaert, P., Watelet, J. B. Claeys, G., Holtappels, G., Claeys, C., Van Cauwenberge, P., and Bachert, C. (2004). Staphylococcus aureus colonization and IgE antibody formation to enterotoxins is increased in nasal polyposis. J. Allergy Clin. Immunol. 114, 981-983.

Van Zele, T., Vaneechoutte, M. Holtappels, G., Gevaert, P., Van Cauwenberge, P., and Bachert, C. (2008). Detection of enterotoxin DNA in Staphylococcus aureus strains obtained from the middle meatus in controls and nasal polyp patients. Am. J. Rhinol. 22, 223-227.

Varshney, A. K., Mediavilla, J. R., Robiou, N., Guh, A., Wang, X., Gialanella, P., Levi, M. H., Kreiswirth, B. N., and Fries, B. C. (2009). Diverse enterotoxin gene profiles among clonal complexes of Staphylococcus aureus isolates from the Bronx, New York. Appl. Environ. Microbiol. 75, 6839-6849.

Vergeront, J. M., Stolz, S. J., Crass, B. A., Nelson, D. B., Davis, J. P., and Bergdoll, M. S. (1983). Prevalence 
of serum antibody to staphylococcal enterotoxin $\mathrm{F}$ among Wisconsin residents: implications for toxicshock syndrome. J. Infect. Dis. 148, 692-698.

Verkaik, N. J., Benard, M., Boelens, H. A., De Vogel, C. P., Nouwen, J. L., Verbrugh, H. A., Melles, D. C., Van Belkum, A., and Van Wamel, W. J. (2011). Immune evasion cluster-positive bacteriophages are highly prevalent among human Staphylococcus aureus strains, but they are not essential in the first stages of nasal colonization. Clin. Microbiol. Infect. 17, 343-348.

Verkaik, N. J., De Vogel, C. P., Boelens, H. A., Grumann, D., Hoogenboezem, T., Vink, C., Hooijkaas, H., Foster, T. J., Verbrugh, H. A., Van Belkum, A., and Van Wamel, W. J. (2009). Anti-staphylococcal humoral immune response in persistent nasal carriers and noncarriers of Staphylococcus aureus. J. Infect. Dis. 199, 625-632.

von Eiff, C., Becker, K., Machka, K., Stammer, H., and Peters, G. (2001). Nasal carriage as a source of Staphylococcus aureus bacteremia. Study Group. N. Engl. J. Med. 344, 11-16.
Wen, R., Cole, G. A., Surman, S., Blackman, M. A., and Woodland, D. L. (1996). Major histocompatibility complex class II-associated peptides control the presentation of bacterial superantigens to T cells. J. Exp. Med. 183, 1083-1092.

Wertheim, H. F., Melles, D. C., Vos, M. C., Van Leeuwen, W., Van Belkum, A., Verbrugh, H. A., and Nouwen, J. L. (2005). The role of nasal carriage in Staphylococcus aureus infections. Lancet Infect. Dis. 5, 751-762.

Wertheim, H. F., Vos, M. C., Ott, A., Van Belkum, A., Voss, A., Kluytmans, J. A., Van Keulen, P. H., Vandenbroucke-Grauls, C. M., Meester, M. H., and Verbrugh, H. A. (2004). Risk and outcome of nosocomial Staphylococcus aureus bacteraemia in nasal carriers versus non-carriers. Lancet 364, 703-705.

White, M. C., Thornton, K., and Young, A. E. (2005). Early diagnosis and treatment of toxic shock syndrome in paediatric burns. Burns 31, 193-197.

Wilson, G. J., Seo, K. S., Cartwright, R. A., Connelley, T., Chuang-Smith, O. N., Merriman, J. A., Guinane, C. M., Park, J. Y., Bohach, G. A.,
Schlievert, P. M., Morrison, W I., and Fitzgerald, J. R. (2011) A novel core genome-encoded superantigen contributes to lethality of community-associated MRSA necrotizing pneumonia. PLoS Pathog. 7:e1002271. doi: 10.1371/journal.ppat.1002271

Yamasaki, S., Tachibana, M., Shinohara, N., and Iwashima, M. (1997). Lck-independent triggering of T-cell antigen receptor signal transduction by staphylococcal enterotoxins. J. Biol. Chem. 272, 14787-14791.

Yeung, R. S. (2007). Lessons learned from an animal model of Kawasaki disease. Clin. Exp. Rheumatol. 25, S69-S71.

Yeung, R. S. (2010). Kawasaki disease: update on pathogenesis. Curr. Opin. Rheumatol. 22, 551-560.

Yeung, R. S., Penninger, J. M., Kundig, T., Khoo, W., Ohashi, P. S., Kroemer G., and Mak, T. W. (1996). Human CD4 and human major histocompatibility complex class II (DQ6) transgenic mice: supersensitivity to superantigen-induced septic shock. Eur. J. Immunol. 26 1074-1082.

Yoshioka, T., Matsutani, T., Iwagami, S., Toyosaki-Maeda, T., Yutsudo, T.
Tsuruta, Y., Suzuki, H., Uemura, S., Takeuchi, T., Koike, M., and Suzuki, R. (1999). Polyclonal expansion of TCRBV2- and TCRBV6bearing $\mathrm{T}$ cells in patients with Kawasaki disease. Immunology 96, 465-472.

Conflict of Interest Statement: The authors declare that the research was conducted in the absence of any commercial or financial relationships that could be construed as a potential conflict of interest.

Received: 01 February 2012; accepted: 29 March 2012; published online: 17 April 2012.

Citation: Xu SX and McCormick JK (2012) Staphylococcal superantigens in colonization and disease. Front. Cell. Inf. Microbio. 2:52. doi: 10.3389/fcimb. 2012.00052

Copyright (C) 2012 Xu and McCormick. This is an open-access article distributed under the terms of the Creative Commons Attribution Non Commercial License, which permits non-commercial use, distribution, and reproduction in other forums, provided the original authors and source are credited. 